\title{
Creation of persistent charge-transfer interactions in TCNQ polyester
}

\author{
Yusuke Washino $^{1}$, Kimie Murata ${ }^{2}$, Minoru Ashizawa $^{1}$, Susumu Kawauchi ${ }^{1}$ and Tsuyoshi Michinobu $^{2,3}$
}

A 7,7,8,8-tetracyanoquinodimethane polyester was converted into a strongly colored polyester with low-energy charge-transfer (CT) bands by treatment with electron-rich alkyne molecules under mild conditions. The post-functionalization was monitored by its ultraviolet-visible-near infrared (IR) spectra, which suggested a quantitative addition reaction without any side reactions. This result was further supported by ${ }^{1} \mathrm{H}$ and ${ }^{13} \mathrm{C}$ nuclear magnetic resonance, IR and elemental analyses. The functionalized polymer retained a high thermal stability with a decomposition onset temperature of $\sim 200{ }^{\circ} \mathrm{C}$ and $\sim 63 \%$ residual soot at $500{ }^{\circ} \mathrm{C}$. The CT chromophores in the polymer showed a clear positive solvatochromism and redox behaviors in both anodic and cathodic directions. The HOMO and LUMO levels estimated from the first oxidation potential $\left(E_{\mathrm{ox}, 1}\right)$ and the first reduction potential $\left(E_{\text {red,1 }}\right)$, respectively, were markedly elevated by this post-functionalization. The extent of HOMO elevation (1.45 eV) was more significant than that of LUMO elevation $(0.44 \mathrm{eV})$.

Polymer Journal (2011) 43, 364-369; doi:10.1038/pj.2011.2; published online 2 February 2011

Keywords: addition reaction; charge transfer; electrochemistry; post-functionalization

\section{INTRODUCTION}

Since the pioneering work on conducting polyacetylene films, ${ }^{1}$ p-type doping of conjugated polymers has been investigated for creating conducting and magnetic organic polymers. ${ }^{2-5}$ For example, the addition of p-type doping reagents, such as tetracyanoethylene, 7,7,8,8-tetracyanoquinodimethane (TCNQ) and their derivatives, to electron-rich polymers produces open-shell polymers because of the charge-transfer (CT) complexation. ${ }^{6-10}$ However, a similar approach using the combination of n-type doping reagents and electrondeficient polymers is rare, probably because of the difficulty of preparing precursor polymers, namely electron-deficient conjugated polymers, and the limited chemical stability of the $\mathrm{n}$-doped polymers at room temperature.

To improve the chemical stability of doped polymers, chemical reactions using cyano-containing p-type doping reagents rather than redox reactions were recently proposed. ${ }^{11}$ The chemical reactions include the thermal [2+2] cycloaddition between electron-rich alkynes and electron-deficient ethene moieties of acceptor molecules, such as tetracyanoethylene and TCNQ, followed by ring opening of the cyclobutene intermediates formed, yielding the donor-acceptor chromophores, as exemplified in Scheme 1 (see ref. 12). Application of these reactions to polymer reactions corresponds to the post-functionalization of polymers. After post-functionalization, the resulting polymers are chemically stable because of their closed-shell structures, and they possess more intense CT bands than the intermolecular CT complexes because of the strong intramolecular donor-acceptor interactions. Such polymers are promising for optical applications, such as electro-optic materials. The post-functionalization of electronrich polymers, namely aromatic polyamines, thiophene polymers and various anilino-functionalized polymers, has previously been demonstrated. ${ }^{13-18}$

In this paper, the post-functionalization of electron-deficient polymers using the high-yielding addition reaction between electron-rich alkynes and TCNQ moieties is reported for the first time. Because it is known that the preparation of electron-deficient conjugated polymers is difficult, TCNQ polyester ${ }^{19}$ was used as an n-type precursor polymer and a dianilino-substituted acetylene molecule as a p-type reactant. A persistent CT band appeared in the low-energy region. A detailed comparison with the model reaction of small molecules suggested that a quantitative post-functionalization was achieved under mild reaction conditions.

\section{EXPERIMENTAL PROCEDURE}

Materials

All reagents were purchased from Kanto (Tokyo, Japan), Wako (Osaka, Japan), Tokyo Kasei (Tokyo, Japan) and Aldrich (St Louis, MO, USA), and used without further purification. Solvents for the reactions were distilled before use.

\section{Measurements}

${ }^{1} \mathrm{H}$ and ${ }^{13} \mathrm{C}$ nuclear magnetic resonance (NMR) spectra were measured on a JEOL (Tokyo, Japan) model AL300 spectrometer at $20^{\circ} \mathrm{C}$. Chemical shifts are reported in p.p.m. downfield from $\mathrm{SiMe}_{4}$, using the solvent's residual signal as

${ }^{1}$ Department of Organic and Polymeric Materials, Tokyo Institute of Technology, Tokyo, Japan; ${ }^{2}$ Global Edge Institute, Tokyo Institute of Technology, Tokyo, Japan and ${ }^{3}$ PRESTO, Japan Science and Technology Agency, Tokyo, Japan

Correspondence: Dr T Michinobu, Global Edge Institute, Tokyo Institute of Technology, 2-12-1 Ookayama, Meguro-ku, Tokyo 152-8550, Japan.

E-mail: michinobu.t.aa@m.titech.ac.jp

Received 14 October 2010; revised 14 December 2010; accepted 23 December 2010; published online 2 February 2011 
an internal reference. The resonance multiplicity is described as $s$ (singlet), $\mathrm{d}$ (doublet), $\mathrm{t}$ (triplet) and $\mathrm{m}$ (multiplet). Attenuated total reflectance Fourier transform infrared spectra were recorded on a JASCO FT/IR-4100 spectrometer (JASCO, Tokyo, Japan). Gel permeation chromatography was measured on a JASCO system equipped with polystyrene gel columns using tetrahydrofuran as an eluent at a flow rate of $1.0 \mathrm{ml} \mathrm{min}{ }^{-1}$. Relative molecular weights were determined by comparison with the calibrated standard polystyrenes. Matrixassisted laser desorption/ionization-time of flight mass spectrometry spectra were measured on a Shimadzu/Karatos (Kyoto, Japan) AXIMA-CFR mass spectrometer using dithranol as a matrix. Melting points (m.p.) were measured in open capillaries with a Büchi Melting Point apparatus (Büchi, Flawil, Switzerland) and are uncorrected. Elemental analysis was carried out on a PerkinElmer 2400-Series II CHNS/O Analyzer (PerkinElmer, Boston, MA, USA). Thermogravimetric analysis and differential scanning calorimetry were carried out on a Rigaku ThermoPlus TG8120 and DSC8230 (Rigaku, Tokyo, Japan), respectively, under flowing nitrogen at a scanning rate of $10^{\circ} \mathrm{C} \mathrm{min}-1$. Ultraviolet-visible-near infrared spectra were recorded on a JASCO V-670 spectrophotometer at $20^{\circ} \mathrm{C}$. Cyclic voltammetry measurements were taken at $20^{\circ} \mathrm{C}$ in dehydrated $\mathrm{CH}_{2} \mathrm{Cl}_{2}$ containing $0.1-\mathrm{M}\left(n \mathrm{C}_{4} \mathrm{H}_{9}\right)_{4} \mathrm{NClO}_{4}$ in a classic three-electrode cell. The working, reference and auxiliary electrodes were a glassy carbon disk electrode $\left(2 \mathrm{~mm}\right.$ in diameter), $\mathrm{Ag} / \mathrm{AgCl} / \mathrm{CH}_{3} \mathrm{CN} /$ $\left(n \mathrm{C}_{4} \mathrm{H}_{9}\right)_{4} \mathrm{NPF}_{6}$ and a platinum wire, respectively. All potentials are referenced to the ferricinium/ferrocene $\left(\mathrm{Fc}^{+} / \mathrm{Fc}\right)$ couple used as an internal standard.

\section{Synthesis}

[3,6-Bis(dicyanomethylidene)cyclohexa-1,4-diene-1,4-diyl]bis(oxyethane-2,1-diyl) dioctanoate (1). To 2,2'-[2,5-bis(2-hydroxyethoxy)cyclohexa-2,5-diene-1,4diylidene]dipropanedinitrile $(5.5 \mathrm{mg}, 17.0 \mu \mathrm{mol})$ in dehydrated dimethyl formamide $(1 \mathrm{ml})$ was added octanoyl chloride $(20 \mu \mathrm{l}, 0.13 \mathrm{mmol})$, and the solution was stirred at $20^{\circ} \mathrm{C}$ for $6.5 \mathrm{~h}$. Column chromatography $\left(\mathrm{SiO}_{2}\right.$, $\mathrm{CH}_{2} \mathrm{Cl}_{2}$ /acetone 20:1) yielded the desired compound (5.1 mg, 52\%).

M.p. $82-84^{\circ} \mathrm{C}$; ${ }^{1} \mathrm{H}$ NMR $\left(300 \mathrm{MHz}, \mathrm{CDCl}_{3}, 293 \mathrm{~K}\right) \delta 0.87(\mathrm{t}, J=9 \mathrm{~Hz}, 6 \mathrm{H})$, $1.29(\mathrm{~m}, 16 \mathrm{H}), 1.61(\mathrm{~m}, 4 \mathrm{H}), 2.34(\mathrm{t}, J=7.5 \mathrm{~Hz}, 4 \mathrm{H}), 4.37-4.52(\mathrm{~m}, 8 \mathrm{H})$, 6.46 p.p.m. (s, $2 \mathrm{H}) ;{ }^{13} \mathrm{C} \mathrm{NMR}\left(75 \mathrm{MHz}, \mathrm{CDCl}_{3}, 293 \mathrm{~K}\right) \delta 14.0,22.5,24.6,28.8$, 29.0, 31.6, 33.9, 60.5, 68.7, 82.8, 103.5, 112.6, 113.1, 147.5, 154.8, 173.5 p.p.m.;

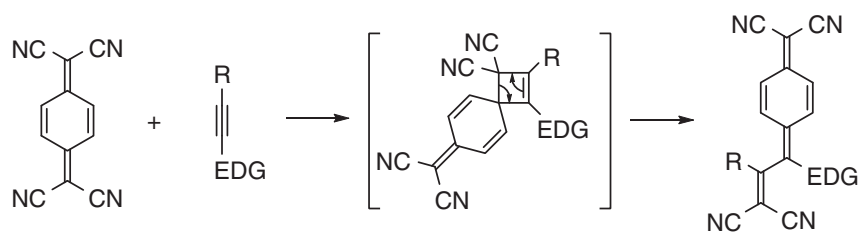

Scheme 1 Reaction mechanism of a high-yield addition reaction between alkynes activated by electron-donating groups (EDGs) and 7,7,8,8tetracyanoquinodimethane.
IR (neat): $v$ 2922, 2853, 2361, 2338, 2203, 1735, 1588, 1537, 1468, 1418, 1364, $1157,942,819 \mathrm{~cm}^{-1}$; matrix-assisted laser desorption/ionization-time of flight mass spectrometry (dithranol): $\mathrm{m} / \mathrm{z}$ : calcd. for $\mathrm{C}_{32} \mathrm{H}_{40} \mathrm{~N}_{4} \mathrm{O}_{6}: 576.29 \mathrm{~g} \mathrm{~mol}^{-1}$; found: $575.63 \mathrm{~g} \mathrm{~mol}^{-1}[M-\mathrm{H}]^{+}$; elemental analysis calcd. (\%) for $\mathrm{C}_{32} \mathrm{H}_{40} \mathrm{~N}_{4} \mathrm{O}_{6}$ (576.68): C 66.65, H 6.99, N 9.72; found: C 66.87, H 7.29, N 9.90.

[(3Z)-3\{3,3-dicyano-1,2-bis[4-(dimethylamino)phenyl]prop-2-en-1-yliden\}-6(dicyanomethylidene)cyclohexa-1,4-diene-1,4-diyl]bis(oxyethane-2,1-diyl) dioctanoate (2). Compound $\mathbf{1}(6.61 \mathrm{mg}, 25.0 \mu \mathrm{mol})$ and 4,4'-(ethyne-1,2-diyl)bis $(N, N$-dimethylaniline $)(14.4 \mathrm{mg}, 25.0 \mu \mathrm{mol})$ in 1,2 -dichloroethane $(12 \mathrm{ml})$ were heated to $60^{\circ} \mathrm{C}$ for 8 days. After cooling to $20^{\circ} \mathrm{C}$, the solvent was removed in vacuo, yielding the desired product (21.0 mg, quant.)

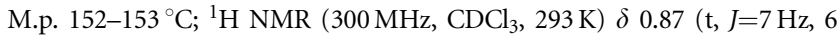
$\mathrm{H}), 1.25-1.27(\mathrm{~m}, 16 \mathrm{H}), 1.60-1.62(\mathrm{~m}, 4 \mathrm{H}), 2.34(\mathrm{t}, J=7.5 \mathrm{~Hz}, 4 \mathrm{H}), 3.08(\mathrm{~s}, 6$ $\mathrm{H}), 3.09(\mathrm{~s}, 6 \mathrm{H}), 3.92-4.45(\mathrm{~m}, 8 \mathrm{H}), 6.33(\mathrm{~s}, 1 \mathrm{H}), 6.55(\mathrm{~s}, 1 \mathrm{H}), 6.60(\mathrm{~d}$, $J=9 \mathrm{~Hz}, 2 \mathrm{H}), 6.68(\mathrm{~d}, J=9 \mathrm{~Hz}, 2 \mathrm{H}), 7.25(\mathrm{~d}, J=9 \mathrm{~Hz}, 2 \mathrm{H}), 7.72$ p.p.m. (d, $J=9 \mathrm{~Hz}, 2 \mathrm{H}) ;{ }^{13} \mathrm{C}$ NMR $\left(75 \mathrm{MHz}, \mathrm{CDCl}_{3}, 293 \mathrm{~K}\right) \delta 14.1,22.6,24.7,28.91$, 28.92, 29.0, 31.6, 33.9, 34.0, 39.9, 40.0, 53.4, 61.2, 61.3, 67.1, 67.6, 77.2, 83.8, $102.0,110.5,111.3,111.9,114.7,115.5,115.7,116.2,120.7,124.7,126.3,132.2$, 133.7, 149.4, 149.9, 152.0, 153.1, 158.3, 172.8, 173.7, 173.9 p.p.m.; IR (neat): $v$ 2922, 2852, 2361, 2338, 2203, 1736, 1588, 1537, 1492, 1418, 1364, 1157, 942, $820 \mathrm{~cm}^{-1}$; matrix-assisted laser desorption/ionization-time of flight mass spectrometry (dithranol): $m / z$ : calcd. for $\mathrm{C}_{50} \mathrm{H}_{60} \mathrm{~N}_{6} \mathrm{O}_{6}: 840.5 \mathrm{~g} \mathrm{~mol}^{-1}$; found: $838.8 \mathrm{~g} \mathrm{~mol}^{-1}[M-\mathrm{H}]^{+}$; elemental analysis calcd. (\%) for $\mathrm{C}_{50} \mathrm{H}_{60} \mathrm{~N}_{6} \mathrm{O}_{6}$ (841.05): C 71.40, H 7.19, N 9.99; found: C 69.20, H 7.11, N 9.49.

TCNQ polyester (P1). 2,2'-[2,5-Bis(2-hydroxyethoxy)cyclohexa-2,5-diene1,4-diylidene]dipropanedinitrile $(302 \mathrm{mg}, 0.932 \mathrm{mmol})$ and sebacoyl chloride $(0.200 \mathrm{ml}, 0.937 \mathrm{mmol})$ were stirred in dehydrated $N, N$-dimethylacetamide $(10 \mathrm{ml})$ at $20^{\circ} \mathrm{C}$ for $48 \mathrm{~h}$. The solution was poured into $\mathrm{MeOH}$, and the precipitate was collected. Reprecipitation into $\mathrm{MeOH}$ yielded the desired TCNQ polyester (302 $\mathrm{mg}, 92 \%$ ).

Gel permeation chromatography (tetrahydrofuran) $M_{\mathrm{w}} 5000, M_{\mathrm{n}} 4400 ;{ }^{1} \mathrm{H}$ $\operatorname{NMR}\left(300 \mathrm{MHz}, \mathrm{CDCl}_{3}, 293 \mathrm{~K}\right) \delta 1.27(\mathrm{~s}, 8 \mathrm{n} \mathrm{H}), 1.59(\mathrm{~m}, 4 \mathrm{n} \mathrm{H}), 2.36(\mathrm{t}$, $J=7.5 \mathrm{~Hz}, 4 \mathrm{n} \mathrm{H}), 4.00-4.80$ (m, 8n H), 6.45 p.p.m. (s, 2n H); ${ }^{13} \mathrm{C}$ NMR $\left(75 \mathrm{MHz}, \mathrm{CDCl}_{3}, 293 \mathrm{~K}\right) \delta 24.6,28.9,29.0,33.9,60.6,68.8,82.8,103.6,112.7$, 113.2, 147.6, 154.9, 173.5 p.p.m.; IR (neat): $v$ 2915, 2849, 2359, 2217, 1727, $1562,1527,1457,1369,1332,1239,1173,1153,1042,993,843,801,719 \mathrm{~cm}^{-1}$; elemental analysis calcd. (\%) for $\left(\mathrm{C}_{26} \mathrm{H}_{26} \mathrm{~N}_{4} \mathrm{O}_{6}\right)_{\mathrm{n}}$ : C 63.66, H 5.34, N 11.42; found: C 62.82, H 5.22, N 11.42.

Donor-acceptor polyester (P2). P1 (51.6 mg, $0.105 \mathrm{mmol}$ ) and 4,4'-(ethyne1,2-diyl)bis( $N, N$-dimethylaniline) $(27.1 \mathrm{mg}, 0.103 \mathrm{mmol})$ in 1,2-dichloroethane ( $7 \mathrm{ml}$ ) were heated to $80^{\circ} \mathrm{C}$ for 3 days. After cooling to $20^{\circ} \mathrm{C}$, the solvent was removed in vacuo, yielding the desired polymer $(78.7 \mathrm{mg}$, quant.).

Gel permeation chromatography (tetrahydrofuran) $M_{\mathrm{w}} 4500, M_{\mathrm{n}} 3700 ;{ }^{1} \mathrm{H}$ NMR $\left(300 \mathrm{MHz}, \mathrm{CDCl}_{3}, 293 \mathrm{~K}\right) \delta 1.26(\mathrm{~m}, 8 \mathrm{n} \mathrm{H}), 2.31(\mathrm{~m}, 4 \mathrm{n} \mathrm{H}), 3.06(\mathrm{~s}, 6 \mathrm{H})$, $3.07(\mathrm{~s}, 6 \mathrm{H}), 3.61(\mathrm{~m}, 4 \mathrm{n} \mathrm{H}), 3.93-4.23(\mathrm{~m}, 8 \mathrm{n} \mathrm{H}), 6.30(\mathrm{~s}, \mathrm{n} \mathrm{H}), 6.54-6.89$

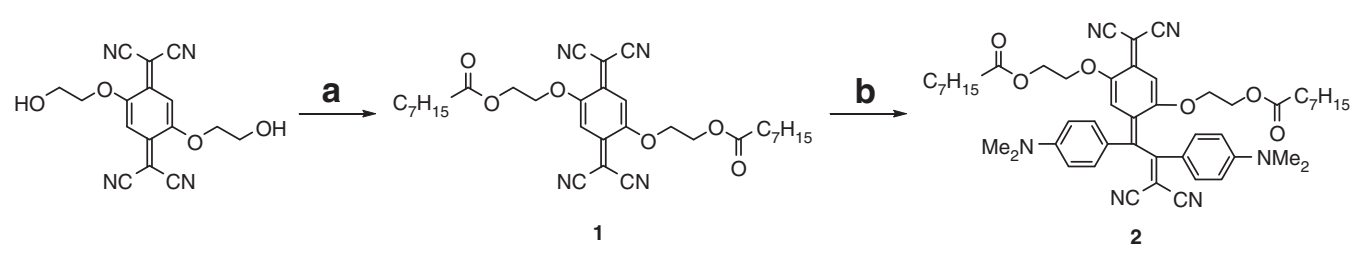

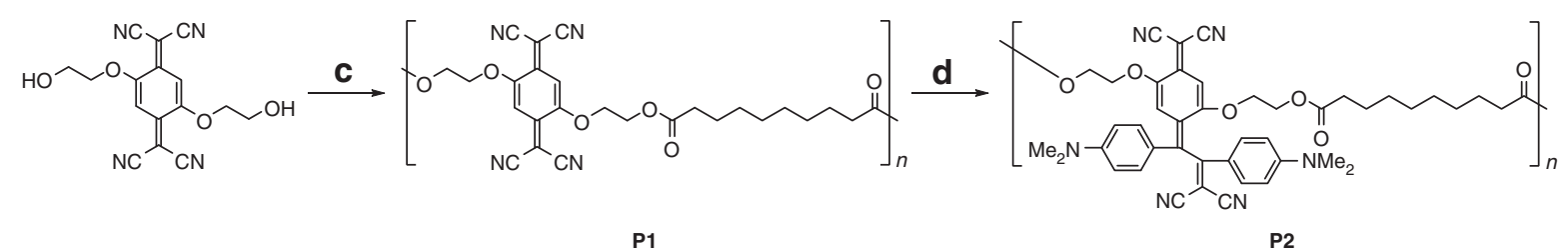

Scheme 2 Synthesis and reaction of 7,7,8,8-tetracyanoquinodimethane diester and polyester. (a) Octanoyl chloride, dimethyl formamide, $20{ }^{\circ} \mathrm{C}, 6.5 \mathrm{~h}, 52 \%$; (b) $\mathrm{Me}_{2} \mathrm{NPhC} \equiv \mathrm{CPhNMe}_{2}, 1,2$-dichloroethane, $60^{\circ} \mathrm{C}$, 8 days, $100 \%$; (c) sebacoyl chloride, $\mathrm{N}, \mathrm{N}$-dimethylacetamide, $20^{\circ} \mathrm{C}, 48 \mathrm{~h} ;\left(\right.$ d) $\mathrm{Me}_{2} \mathrm{NPhC} \equiv \mathrm{CPhNMe}$, 1,2-dichloroethane, $80^{\circ} \mathrm{C}, 3$ days. 
(m, 5n H), 7.25 (s, 2n H), 7.69 p.p.m. (s, $J=4.4 \mathrm{~Hz}, 2 \mathrm{n} \mathrm{H}) ;{ }^{13} \mathrm{C}$ NMR $(75 \mathrm{MHz}$, $\left.\mathrm{CDCl}_{3}, 293 \mathrm{~K}\right) \delta 24.7,29.0,29.1,29.6,33.8,34.0,39.9,40.0,40.3,61.2,61.3,67.1$, $67.6,77.2,102.0,110.7,111.3,111.9,114.8,115.6,115.7,116.3,120.6,124.6,126.3$, 133.8, 134.0, 149.4, 149.7, 150.0, 152.1, 153.1, 158.4, 172.8, 173.6, 173.8 p.p.m.; IR (neat): v 2925, 2359, 2341, 2202, 1732, 1586, 1530, 1487, 1414, 1362, 1333, $1207,1155,1060,943,819,731,650 \mathrm{~cm}^{-1}$; elemental analysis calcd. (\%) for $\left(\mathrm{C}_{44} \mathrm{H}_{46} \mathrm{~N}_{6} \mathrm{O}_{6}\right)_{\mathrm{n}}$ : C 70.01, H 6.14, N 11.13; found: C 68.21, H 6.27, N 10.58.

\section{RESULTS AND DISCUSSION}

\section{Synthesis and characterization}

A precursor polymer, the TCNQ polyester, was prepared by polycondensation between sebacoyl chloride and the commercially available TCNQ derivative with two $\mathrm{OH}$ groups, according to a previous report on a similar TCNQ polyester synthesis ${ }^{19}$ (Scheme 2). Although the previous report did not describe the molecular weights of the TCNQ polymers obtained, the molecular weights of $\mathbf{P 1}$ were measured by gel permeation chromatography. The weight-average molecular weight $\left(M_{\mathrm{w}}\right)$ and number-average molecular weight $\left(M_{\mathrm{n}}\right)$ were 5000 and 4400 , respectively, corresponding to a monomer repeat unit $(n)$ of $\sim 8$. The relatively low polydispersity $\left(M_{\mathrm{w}} / M_{\mathrm{n}}\right)$ suggests the partial adsorption of $\mathbf{P} \mathbf{1}$ on the polystyrene gel.

A monomer unit $\mathbf{1}$ was also prepared for comparison with $\mathbf{P 1}$. The addition reaction of 1 with $\mathrm{Me}_{2} \mathrm{NPhC} \equiv \mathrm{CPhNMe}_{2}$ was first conducted in $\mathrm{CH}_{2} \mathrm{Cl}_{2}$ at $20^{\circ} \mathrm{C}$. A slight coloration occurred after stirring overnight, but no isolatable amount of 2 was obtained. On the basis of the quantitative addition yield of $\mathrm{Me}_{2} \mathrm{NPhC} \equiv \mathrm{CPhNMe}_{2}$ to TCNQ at

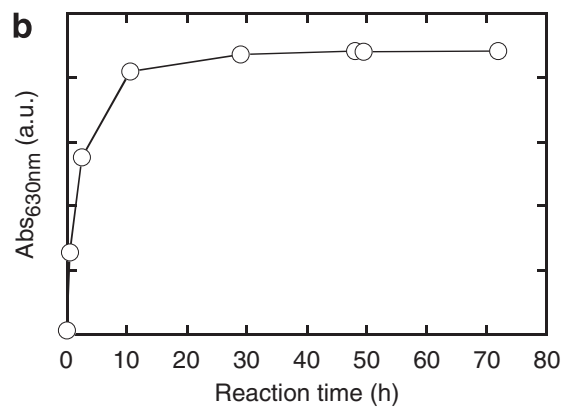

Figure 1 (a) Ultraviolet-visible-near infrared spectral change during the preparation of $\mathbf{P} 2$ from $\mathbf{P} 1$ and an equivalent amount of 4,4'-(ethyne-1,2$\operatorname{diyl})$ bis $\left(N, N\right.$-dimethylaniline) in 1,2 -dichloroethane at $80^{\circ} \mathrm{C}$. (b) Plots of time versus intensities of the charge-transfer band at $630 \mathrm{~nm}$.

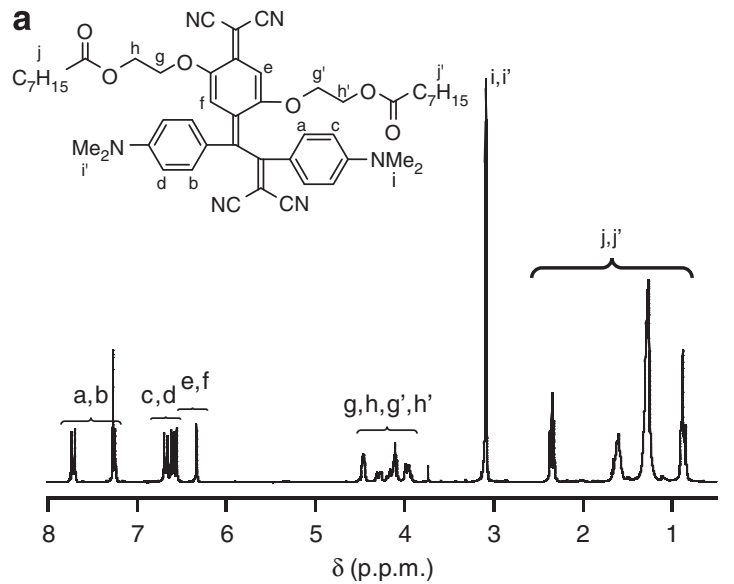

b

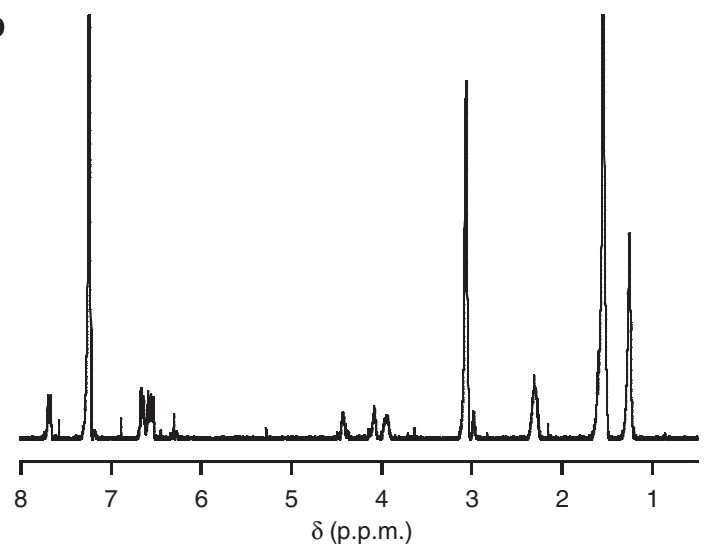

C

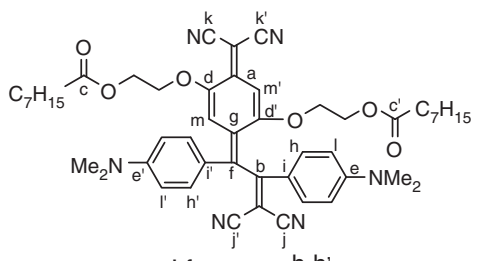

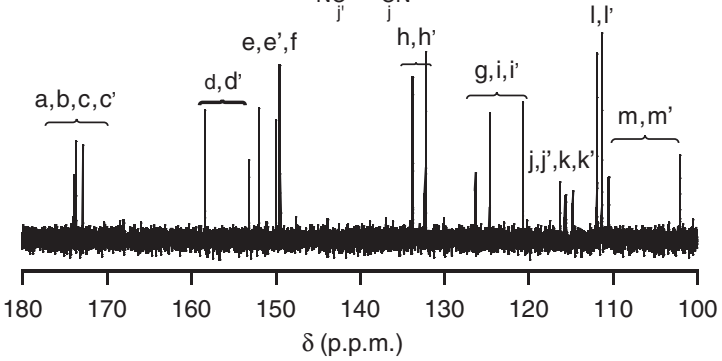

d

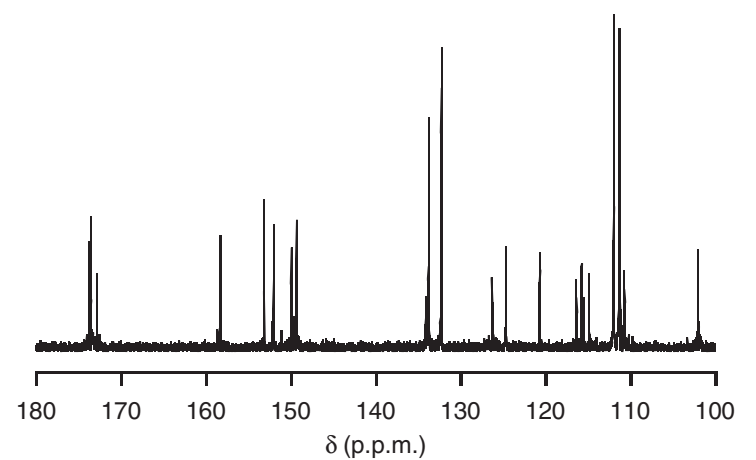

Figure $2{ }^{1} \mathrm{H}$ nuclear magnetic resonance (NMR) spectra of (a) 2 and (b) $\mathrm{P} 2$ in $\mathrm{CDCl}_{3}$ at $20{ }^{\circ} \mathrm{C}$ and the aromatic region of ${ }^{13} \mathrm{C} \mathrm{NMR} \mathrm{spectra} \mathrm{of} \mathrm{(c)} 2$ and (d) $\mathbf{P 2}$ in $\mathrm{CDCl}_{3}$ at $20^{\circ} \mathrm{C}$. 
$20^{\circ} \mathrm{C}$ (see ref. 20), it was probably caused by the decreased reactivity of the TCNQ moiety because of the substitution of the two electrondonating alkyloxy groups. Replacement of the solvent by 1,2-dichloroethane and slight heating started to change the solution color from orange to green. After a sufficient reaction time, the desired product 2 was quantitatively obtained. On the basis of this knowledge, the post-functionalization of $\mathbf{P} 2$ was attempted. The heating of $\mathbf{P 2}$ and $\mathrm{Me}_{2} \mathrm{NPhC} \equiv \mathrm{CPhNMe}_{2}$ in 1,2-dichloroethane to $80^{\circ} \mathrm{C}$ (near boiling point) gradually changed the solution color, implying that the reaction was occurring. The time-dependent spectral change in the ultravioletvisible-near infrared absorption was monitored (Figure 1a). P1 possessed absorption maxima at 434 and $412 \mathrm{~nm}$, which are ascribed to the dialkyloxy-substituted TCNQ moieties. When the post-functionalization occurred, the intensity of these peaks started to increase and they fused into a single broad peak. In contrast, the weak peaks at

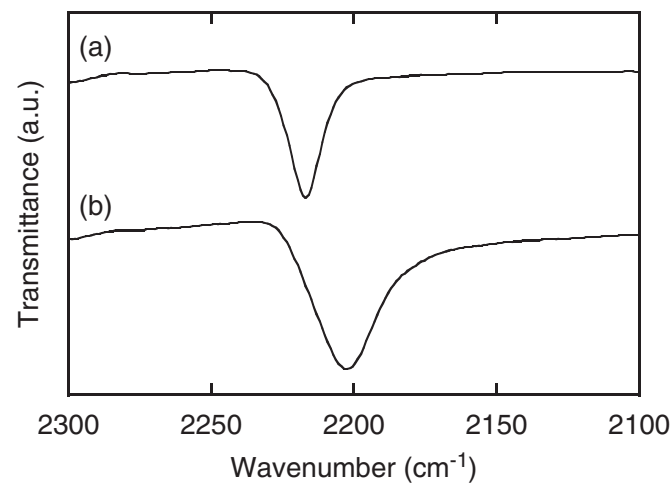

Figure 3 Attenuated total reflectance Fourier transform infrared spectra (neat) of (a) P1 and (b) P2.

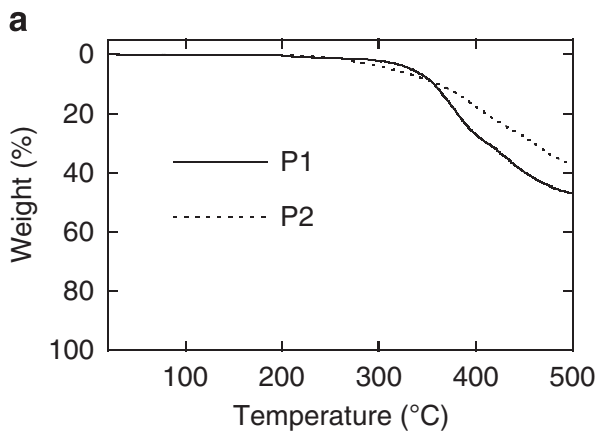

Figure 4 (a) Thermogravimetric analysis and (b) differential scanning calorimetry thermograms (second heating) of P1 and P2 at the scanning rate of $10{ }^{\circ} \mathrm{min}^{-1}$ under nitrogen flow.

Table 1 Summary of $\lambda_{\max }$ values in different solvents at $20^{\circ} \mathrm{C}$

\begin{tabular}{|c|c|c|c|c|c|}
\hline Solvent & $\mathrm{E}_{T}(30) / \mathrm{kcal} \mathrm{mol}^{-1}$ & $1 / n m(e V)$ & $2 / n m(e V)$ & $P 1 / n m(e V)$ & $P 2 / n m(e V)$ \\
\hline Cyclohexane & 30.9 & $426(2.91)$ & $555(2.23)$ & $425(2.92)$ & $-^{a}$ \\
\hline Benzene & 34.3 & $440(2.82)$ & $608(2.04)$ & $426(2.91)$ & $591.5(2.10)$ \\
\hline Diethyl ether & 34.5 & $420(2.95)$ & $581(2.13)$ & $430.5(2.88)$ & $-^{a}$ \\
\hline Tetrahydrofuran & 37.4 & $433(2.86)$ & $609.5(2.03)$ & $434(2.86)$ & $614(2.02)$ \\
\hline Dichlorobenzene & 38.0 & $441(2.81)$ & $629(1.97)$ & $440(2.82)$ & $633(1.96)$ \\
\hline Ethyl acetate & 38.1 & $429.5(2.89)$ & $625.5(1.98)$ & $426.5(2.91)$ & $-^{a}$ \\
\hline Chloroform & 39.1 & $433(2.86)$ & $620(2.00)$ & $434(2.86)$ & $625.5(1.98)$ \\
\hline Dichloromethane & 40.7 & $432.5(2.87)$ & $625.5(1.98)$ & $433.5(2.86)$ & 628.5 (1.97) \\
\hline
\end{tabular}

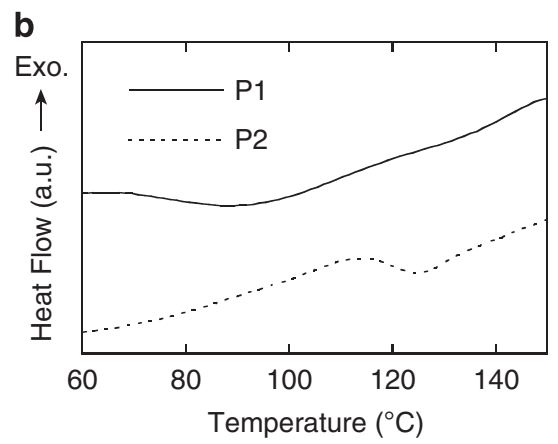

$<360 \mathrm{~nm}$ decreased. The presence of the isosbestic point at $360 \mathrm{~nm}$ indicated that there were no undesired side reactions during postfunctionalization. In addition, a well-defined low-energy band appeared at $630 \mathrm{~nm}$, which is ascribed to the CT transition from the dimethylanilino donors to the cyano-based acceptor moieties. The intensity of this CT band was plotted against the reaction time (Figure 1b). The plots suggest that the reaction was almost completed after $30 \mathrm{~h}$, and prolongation did not result in any degradation of the donoracceptor chromophores formed.

The obtained donor-acceptor chromophores were fully characterized. In the ${ }^{1} \mathrm{H}$ and ${ }^{13} \mathrm{C}$ NMR spectra of 2 , all peaks were assigned to the single chemical structure, despite the possibilities of $E$ - and $Z$ isomers (Figures $2 \mathrm{a}$ and $\mathrm{c}$ ). To estimate the relative stability of these isomers, computational calculations were carried out for the simplified model structures at the $\omega \mathrm{B} 97 \mathrm{XD} / 6-31 \mathrm{G}^{*}$ level (see Supplementary Information). These calculations suggested that the $Z$-form is energetically preferred by $11.4 \mathrm{~kJ} \mathrm{~mol}^{-1}$ compared with the $E$-form. Therefore, the obtained product is assumed to be the $Z$-isomer. The matrixassisted laser desorption/ionization-time of flight mass spectrometry and elemental analysis were also consistent with the chemical structure. The ${ }^{1} \mathrm{H}$ NMR spectrum of $\mathbf{P} \mathbf{2}$ was similar to that of $\mathbf{2}$, although some peaks were broader because of the polymer effect (Figure $2 \mathrm{~b}$ ). The number of ${ }^{13} \mathrm{C}$ NMR peaks in the aromatic region agreed with that of $\mathbf{2}$ or with the chemical structure of the monomer repeat unit (Figure 2d). The IR spectra of $\mathbf{P 1}$ and $\mathbf{P} 2$ revealed the difference in the cyano vibrational peak positions. The cyano peak of P1 detected at $2217 \mathrm{~cm}^{-1}$ completely disappeared after the post-functionalization, and a new cyano peak appeared at $2202 \mathrm{~cm}^{-1}$ (Figure 3). This shift is consistent with the previous report. ${ }^{15}$ All these results support the clean post-functionalization of the TCNQ polyester by an addition reaction with electron-rich alkyne molecules. 


\section{Thermal properties}

The obtained polymers were chemically and thermally stable. The thermogravimetric analysis of $\mathbf{P} \mathbf{1}$ and $\mathbf{P} \mathbf{2}$ was carried out at a heating rate of $10{ }^{\circ} \mathrm{C} \mathrm{min}^{-1}$ under flowing nitrogen. Both polymers showed no decomposition at least up to $200^{\circ} \mathrm{C}$, suggesting that the high thermal stability was retained after the post-functionalization (Figure 4a). This result is consistent with the previous results for the post-functionalization of p-type-conjugated polymers. ${ }^{13,17}$ The residual soot amount of P2 (63\%) was greater than that of P1 (53\%), reflecting the aromatic contents in the polymers. The enhanced intermolecular interactions of P2 with additional aromatic rings were implied by the melting points of the small molecules $\left(1: 82-84^{\circ} \mathrm{C}, 2\right.$ : $\left.152-153{ }^{\circ} \mathrm{C}\right)$. The weak intermolecular interactions based on the $\pi-\pi$ interactions and dipolar interactions might also be associated with the increased amount of soot at $500{ }^{\circ} \mathrm{C}$. Both polymers $\mathbf{P} 1$ and $\mathbf{P} 2$ displayed a glass transition temperature $\left(T_{\mathrm{g}}\right)$ at 87 and $123^{\circ} \mathrm{C}$, respectively, in the differential

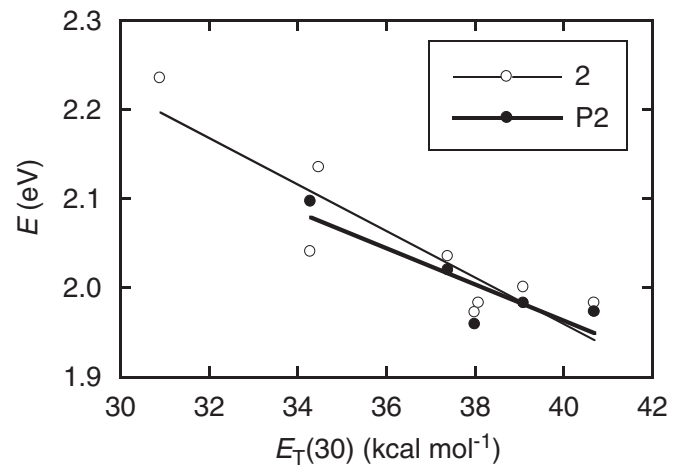

Figure 5 Relationship between the solvent polarity parameter $E_{\mathrm{T}}(30)$ and the charge-transfer band maxima of $\mathbf{2}$ and $\mathbf{P} \mathbf{2}$.

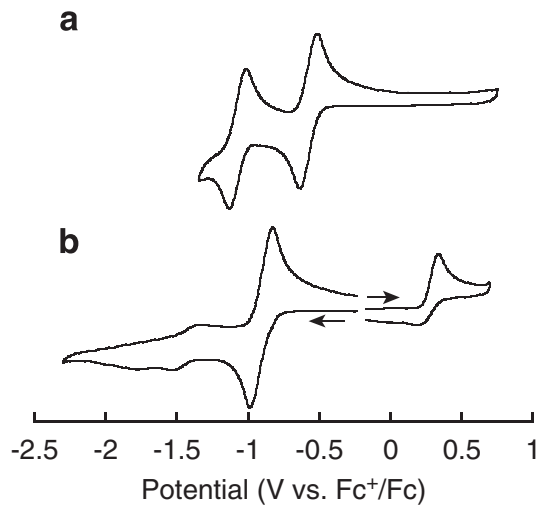

scanning calorimetry thermograms (Figure $4 \mathrm{~b}$ ). It is thought that the higher $T_{\mathrm{g}}$ of $\mathbf{P 2}$ is also derived from the enhanced intermolecular interactions.

\section{Optical and electrochemical measurements}

The formation of stable CT bands was evaluated by ultraviolet-visiblenear infrared absorption spectra in various solvents, and the energy levels were estimated from the end absorptions and electrochemical redox potentials.

As shown in Figure 1a, the addition reaction produced a low-energy band in the ultraviolet-visible-near infrared region. These bands were chemically persistent in various solvents, and the $\lambda_{\max }$ values are summarized as a function of solvent polarity $E_{\mathrm{T}}(30)$ (Table 1). Similar to many donor-acceptor chromophores prepared by this class of addition reactions, ${ }^{21-23}$ both $\mathbf{2}$ and $\mathbf{P} 2$ displayed a positive solvatochromism with a correlation coefficient of $\sim 0.90$ (Figure 5). In contrast, the $\lambda_{\max }$ values of the precursors $\mathbf{1}$ and P1 did not show such behaviors.

To compare the chemical stability of the CT bands with those prepared by the conventional n-type doping, complexation of the TCNQ polyester P1 with tetrathiafulvalene was attempted. However, P1 did not react with tetrathiafulvalene even when the solution was heated to the boiling point of $\mathrm{CHCl}_{3}$, probably because of the cathodic shift of $E_{\text {red,1 }}$ of the TCNQ moieties relative to the unsubstituted TCNQ $\left(E_{\mathrm{red}, 1}=-0.25 \mathrm{~V}\right)$ (see ref. 24 ; vide infra).

Redox potentials are often used to estimate the energy levels of aromatic compounds. Cyclic voltammograms of the polymers and model monomers were measured in $\mathrm{CH}_{2} \mathrm{Cl}_{2}$ containing $0.1-\mathrm{M}$ $\left(n \mathrm{C}_{4} \mathrm{H}_{9}\right)_{4} \mathrm{NClO}_{4}$ at $20^{\circ} \mathrm{C}$. Figure 6 shows the typical cyclic voltammogram curves, and the redox potentials are summarized in Table 2 . The redox behaviors of the polymers were basically the same as those of the corresponding monomers. The precursors displayed the only two

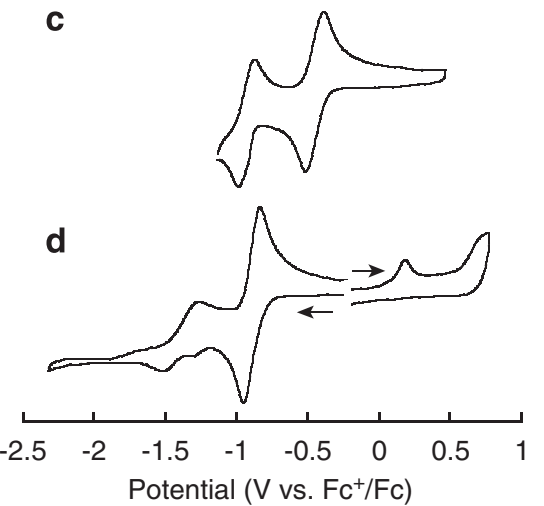

Figure 6 Cyclic voltammograms of (a) 1, (b) 2, (c) $\mathbf{P} 1$ and (d) $\mathbf{P} 2$ in $\mathrm{CH}_{2} \mathrm{Cl}_{2}$ with $0.1-\mathrm{M}\left(n \mathrm{C}_{4} \mathrm{H}_{9}\right)_{4} \mathrm{NClO}_{4}$ at the scan rate of $0.1 \mathrm{Vs}^{-1}$ under nitrogen.

Table 2 Summary of electrochemical and optical measurements

\begin{tabular}{|c|c|c|c|c|c|c|c|}
\hline & $\mathrm{E}_{r e d 2} / V^{A}$ & $\mathrm{E}_{\text {red1 }} / N^{A}$ & $\mathrm{E}_{o x 1} / N^{a, b}$ & $\Delta / \mathbb{E}_{o x 1}-\mathrm{E}_{r e d 1} / N$ & Opt. band gap/ev & HOMO/eV & LUMO/eV \\
\hline 1 & -0.93 & -0.46 & - & - & 2.32 & $-6.61^{e}$ & -4.29 \\
\hline 2 & -1.44 & -0.90 & 0.34 & 1.24 & 1.41 & $-5.38^{d}$ & -3.97 \\
\hline P1 & -0.96 & -0.47 & - & - & 2.28 & $-6.71^{\mathrm{e}}$ & -4.43 \\
\hline P2 & -1.29 & -0.92 & 0.19 & 1.11 & 1.27 & $-5.26^{d}$ & -3.99 \\
\hline
\end{tabular}

aRedox potentials measured in $\mathrm{CH}_{2} \mathrm{Cl}_{2}$ with $0.1 \mathrm{M}\left(n \mathrm{C}_{4} \mathrm{H}_{9}\right)_{4} \mathrm{NClO}_{4}$ at $20^{\circ} \mathrm{C}$. Potentials versus $\mathrm{Fc}^{+} / \mathrm{Fc}$.

beak top values.

CMeasured in $\mathrm{CH}_{2} \mathrm{Cl}_{2}$ at $20^{\circ} \mathrm{C}$

${ }^{d}$ Calculated from the $E_{0 \times 1}$ and $E_{\text {red } 1}$ values based on the assumed value of $\mathrm{Fc}^{+} / \mathrm{Fc}=-4.8 \mathrm{eV}$.

eCalculated from the electrochemically determined LUMO level and optical band gap. 
reversible reduction steps at the first reduction potential $\left(E_{\mathrm{red}, 1}\right)$ of -0.46 and the second reduction potential $\left(E_{\text {red,2 }}\right)$ of $-0.93 \mathrm{~V}\left(\mathrm{vs} \mathrm{Fc}^{+} /\right.$ Fc) for 1 and at $E_{\text {red,1 }}$ of -0.47 and $E_{\text {red,2 }}$ of $-0.96 \mathrm{~V}$ for P1, ascribed to the TCNQ moieties (Figures $6 \mathrm{a}$ and $\mathrm{c}$ ). After the addition reaction with the electron-rich alkyne molecule, the reduction potentials cathodically shifted, and the current intensity of $E_{\text {red,2 }}$ significantly decreased. In addition, a new irreversible oxidation peak $\left(E_{\mathrm{ox}, 1}\right)$ ascribed to the dimethylanilino groups appeared at $0.34 \mathrm{~V}$ for 2 and at $0.19 \mathrm{~V}$ for P2. Different peak top values of $E_{\mathrm{ox}, 1}$ might reflect the stronger adsorption features of $\mathbf{P} 2$ to the working electrode. The calculated electrochemical band gaps $\left(\Delta\left|E_{\mathrm{ox}, 1}-E_{\mathrm{red}, 1}\right|\right)$ of 2 and $\mathbf{P 2}$ were 1.24 and $1.11 \mathrm{~V}$, respectively, which are consistent with the optical band gaps determined by the end absorption in $\mathrm{CH}_{2} \mathrm{Cl}_{2}$. The energy levels estimated from the redox potentials and optical band gaps indicated that both $\mathrm{HOMO}$ and LUMO levels were elevated after the addition reaction. In contrast to the acceptor addition to the p-type precursor polymers resulting in a marked decrease in the LUMO levels, ${ }^{1,25}$ the addition of electron-rich alkyne molecules to the n-type precursor polymers leads to a more significant elevation of HOMO levels than LUMO levels.

\section{CONCLUSION}

The post-functional preparation of persistent intramolecular CT interactions in the n-type precursor polymer was achieved using the addition reaction between the electron-rich alkynes and TCNQ moiety. The quantitative conversion ensures a facilitated preparation protocol without special purification, such as column chromatography. The conventional analytical methods and a comparison with the model reaction of the monomer moiety demonstrated the high purity of the post-functionalized polymer. A sufficiently high thermal stability with the onset decomposition temperature of $\sim 200^{\circ} \mathrm{C}$ was retained even after post-functionalization. The electrochemical and optical measurements clearly revealed the formation of intramolecular CT bands, accompanying the marked change in energy levels. With designable electron-rich alkyne molecules, the TCNQ polymers can serve as a reactive functional polymer for preparing various CT energies.

\section{ACKNOWLEDGEMENTS}

This work was supported, in part, by a Grant-in-Aid for Scientific Research and Special Coordination Funds for Promoting Science and Technology from MEXT, Japan, and the Kato Foundation for Promotion of Science.

1 Shirakawa, H., Louis, E. J., MacDiarmid, A. G., Chiang, C. K. \& Heeger, A. J. Synthesis of electrically conducting organic polymers: halogen derivatives of polyacetylene, $(\mathrm{CH})_{x}$. J. Chem. Soc. Chem. Commun 578-580 (1977).

2 Yamamoto, T., Morita, A., Miyazaki, Y., Maruyama, T., Wakayama, H., Zhou, Z.-h., Nakamura, Y. \& Kanbara, T. Preparation of $\pi$-conjugated poly(thiophene-2,5-diyl), poly(p-phenylene), and related polymers using Zerovalent Nickel complexes. linear structure and properties of the $\pi$-conjugated polymers. Macromolecules 25, 1214 1223 (1992).

3 Michinobu, T., Inui, J. \& Nishide, H. m-Phenylene-linked aromatic poly(aminium cationic radical)s: persistent high-spin organic polyradicals. Org. Lett. 5, 2165-2168 (2003).

4 Michinobu, T., Kato, F., Inui, J. \& Nishide, H. Two-dimensionally extended aromatic polyamines for optimization of charge-transporting properties by partial oxidation. $J$. Polym. Sci.: Part A: Polym. Chem. 47, 4577-4586 (2009).

5 Michinobu, T., Inui, J. \& Nishide, H. Two-dimensionally extended organic high-spin poly(aminium cationic radical)s and their magnetic force microscopic images. Polym. J. 42, 575-582 (2010).

6 Saito, S., Tsutsui, T., Tokito, S., Hara, T. \& Chiu, H.- T. Electron transport in doped and undoped polymers containing $\pi$-conjugated groups. Polym. J. 17, 209-216 (1985).

7 Yoshioka, N., Nishide, H., Inagaki, K. \& Tsuchida, E. Electrical conductive and magnetic properties of conjugated tetrathiolate nickel polymers. Polym. Bull. 23, 631-636 (1990).

8 Naka, K., Uemura, T. \& Chujo, Y. Synthesis of $\pi$-conjugated poly(dithiafulvene) by cycloaddition polymerization of aldothioketene with Its alkynethiol tautomer. Macromolecules 31, 7570-7571 (1998).

9 Oyaizu, K., Mitsuhashi, F. \& Tsuchida, E. Palladium-catalyzed synthesis of oligo(methylthio)aniline and conversion to polyacene-type electrolytes bearing phonothiazinium repeating units. Macromol. Chem. Phys. 203, 1328-1336 (2002).

10 Inagi, S., Naka, K. \& Chujo, Y. Functional polymers based on electron-donating TTF and derivatives. J. Mater. Chem. 17, 4122-4135 (2007).

11 Michinobu, T. Click synthesis of donor-acceptor type aromatic polymers. Pure Appl. Chem. 82, 1001-1009 (2010).

12 Kato, S.-i. \& Diederich, F. Non-planar push-pull chromophores. Chem. Commun. 46, 1994-2006 (2010).

13 Michinobu, T. Click-type reaction of aromatic polyamines for improvement of thermal and optoelectronic properties. J. Am. Chem. Soc. 130, 14074-14075 (2008).

$14 \mathrm{Li}$, Y. \& Michinobu, T. Sequential double click reactions: a highly efficient post-functionalization method for optoelectronic polymers. Polym. Chem. 1, 72-74 (2010).

$15 \mathrm{Li}$, Y., Tsuboi, K. \& Michinobu, T. Double click synthesis and second-order nonlinearities of polystyrenes bearing donor-acceptor chromophores. Macromolecules 43, 5277-5286 (2010).

16 Li, Y., Tsuboi, K., Michinobu, T., Ishida, Y., Hirai, T., Hayakawa, T. \& Kakimoto, M.-a. Efficient synthesis of block copolymers bearing donor-acceptor chromophores for second-order nonlinear optical applications. J. Photopolym. Sci. Technol. 23, 337-342 (2010).

17 Michinobu, T., Kumazawa, H., Noguchi, K. \& Shigehara, K. One-step synthesis of donor-acceptor type conjugated polymers from ferrocene-containing poly(aryleneethynylene)s. Macromolecules 42, 5903-5905 (2009).

18 Wang, D. \& Michinobu, T. One-step synthesis of ladder-type fused poly(benzopentalene) derivatives with tunable energy levels by variable substituents. J. Polym. Sci.: Part A: Polym. Chem. 49, 72-81 (2011).

19 Day, R. W., Inzelt, G., Kinstle, J. F. \& Chambers, J. Q. Tetracyanoquinodimethanemodified electrodes. J. Am. Chem. Soc. 104, 6804-6805 (1982).

20 Kivala, M., Boudon, C., Gisselbrecht, J.- P., Seiler, P., Gross, M. \& Diederich, F. A novel reaction of 7,7,8,8-tetracyanoquinodimethane (TCNQ): charge-transfer chromophores by [2+2] cycloaddition with alkynes. Chem. Commun. 4731-4733 (2007)

21 Michinobu, T., May, J. C., Lim, J. H., Boudon, C., Gisselbrecht, J.- P., Seiler, P., Gross, M., Biaggio, I. \& Diederich, F. A new class of organic donor-acceptor molecules with large third-order optical nonlinearities. Chem. Commun 737-739 (2005).

22 Michinobu, T., Boudon, C., Gisselbrecht, J.- P., Seiler, P., Frank, B., Moonen, N. N. P., Gross, M. \& Diederich, F. Donor-substituted 1,1,4,4-tetracyanobutadienes: new chromophores with efficient intramolecular charge-transfer interactions by atom-economic synthesis. Chem. Eur. J. 12, 1889-1905 (2006).

23 Kivala, M., Stanoeva, T., Michinobu, T., Frank, B., Gescheidt, G. \& Diederich, F. Oneelectron reduced and oxidized stages of donor-substituted 1,1,4,4-tetracyanobuta-1,3dienes of different molecular architectures. Chem. Eur. J. 14, 7638-7647 (2008).

24 Connelly, N. G. \& Geiger, W. E. Chemical redox agents for organometallic chemistry. Chem. Rev. 96, 877-910 (1996).

25 Yuan, Y. \& Michinobu, T. Energy level tuning of polythiophene derivative by click chemistry-type post-functionalization of side chain alkynes. J. Polym. Sci.: Part A: Polym. Chem. 49, 225-233 (2011).

Supplementary Information accompanies the paper on Polymer Journal website (http://www.nature.com/pj) 